\title{
The German National Reference Centre for Authentic Food (NRZ-Authent) ${ }^{\text {is }}$
}

\author{
Bertrand Matthäus*, Ina Willenberg, Stefan Engert and Pablo Steinberg \\ Max Rubner-Institut, Federal Research Institute of Nutrition and Food, 12, Schützenberg, 32756 Detmold, Germany
}

Received 17 December 2018 - Accepted 4 March 2019

\begin{abstract}
The present report describes the establishment, structure and objectives of the recently established German National Reference Center for Authentic Food (NRZ-Authent). The NRZ-Authent is completely integrated into the Max Rubner-Institut (MRI), the Federal Research Institute of Nutrition and Food in Germany. Various different departments of MRI have a long experience regarding the analysis of the quality of food in general and the testing of food authenticity in particular. Therefore, a close interaction between these food-related departments and the NRZ-Authent is a basic requirement for the successful work of this newly created centre. The addressees of the NRZ-Authent are the official food authorities and laboratories in the German states. In this context, the NRZ-Authent will establish a platform for providing quick access to updated, reliable and consistent technical data, research findings, new techniques and expertise necessary for the correct application of European Union legislation. The MRI has been working on the authenticity of edible oils for a number of years now, and some examples of this successful work are presented.
\end{abstract}

Keywords: adulteration / edible oil / food fraud / National Reference Centre for Authentic Food

Résumé - Le Centre national allemand de référence pour l'authenticité des aliments (NRZ-Authent). Le présent rapport décrit la création, la structure et les objectifs du Centre national de référence pour l'authenticité des aliments récemment créé en Allemagne (NRZ-Authent). Le NRZ-Authent est complètement intégré au Max Rubner-Institut (MRI), l'Institut fédéral de recherche sur la nutrition et l'alimentation en Allemagne. Différents départements du MRI possèdent une longue expérience de l'analyse de la qualité des aliments en général et des tests d'authenticité des aliments en particulier. Par conséquent, une interaction étroite entre ces départements liés aux produits alimentaires et le NRZ-Authent est une exigence fondamentale à la réussite de ce centre nouvellement créé. Les destinataires du NRZAuthent sont les autorités alimentaires officielles et les laboratoires des États allemands. Dans ce contexte, le NRZ-Authent créera une plate-forme pour fournir un accès rapide à des données techniques, des résultats de recherche, des nouvelles techniques et des compétences mises à jour, fiables et cohérentes nécessaires à l'application correcte de la législation de l'Union européenne. L'IRM travaille sur l'authenticité des huiles alimentaires depuis plusieurs années et quelques exemples de ce travail sont présentés.

Mots clés : adultération / huile comestible / fraude alimentaire / Centre national de référence pour 1\&apos / authenticité des aliments

\section{Introduction}

Food fraud is not a new phenomenon, since frauds such as the incorrect weight of products, the adulteration of bread with sand instead of flour or the addition of water to oil are known

\footnotetext{
The oil \& protein crop supply chain in Eastern Europe / La filière oléoprotéagineuse en Europe de l'Est

*Correspondence: bertrand.matthaeus@mri.bund.de
}

since thousands of years. But nowadays, food authenticity is on everyone's lips, also at the political level, at the latest since the horse meat scandal in 2013. In this case, foods advertised as containing beef were found to contain undeclared or improperly declared horse meat, in some cases up to $100 \%$ of the meat content, in Europe (BBC News, 2013). In the field of fats and oils, especially olive oil is a lucrative product for adulteration with respect to wrongly labelled quality, not declared or illegal processing or wrong indication of geographical origin, but also other expensive and valuable 
oils such as argan oil, or also cheaper oils purchased in high quantities may be subjected to different kinds of food fraud. Although various European Union (EU) regulations or the specifications of the International Olive Council (IOC) define specific parameters to ensure authenticity and quality of olive oil, extra virgin olive oil is ranking within the top 10 of the most counterfeited food items worldwide.

As a consequence of food fraud, not only the individual consumer is affected by paying money for an inferior product but also the whole processing chain can be ruined. In extreme cases, a health risk for the consumer may also arise from food fraud as in the case of the toxic oil syndrome in 1981, when rapeseed oil denaturated by the addition of aniline was illegally sold as "olive oil" on street markets (Gelpi et al., 2002). In the case of olive oil, most adulterations refer to the different categories of olive oil, i.e. olive oil of an inferior quality, e.g., native olive oil or lampante oil is labelled as olive oil extra virgin. Moreover, the replacement of olive oil by cheaper oil, or the wrongly declared geographical origin of olive oil as an important quality feature are further possibilities to carry out food fraud. A relatively new possible adulteration is the addition of soft-deodorised olive oil to extra virgin olive oils. Soft-deodorisation is a refining step carried out with olive oil of bad sensory quality at low temperature $\left(<100^{\circ} \mathrm{C}\right)$ with the aim of removing sensory defects (García González et al., 2018).

As a consequence of the horsemeat scandal, but also of an increasing consumer uncertainty regarding food quality, the European Union adopted an action plan with the aim of combating food fraud more effectively. The action plan included a variety of measures including advanced training for food inspectors, the police and customs authorities, a new regulation (Regulation [EU] 2017/625, issued on the 15th of March 2017), the launching of an electronic system to exchange data in a structured manner regarding noncompliances with food and feed legislation (EUR-Lex, 2017), the so-called Administrative Assistance and Cooperation System (2017), as well as the creation of an EU Food Fraud Network composed of representatives from the European Commission, all EU countries, Switzerland, Norway and Iceland for a more efficient cross-border administrative assistance and cooperation (Food Fraud, 2018).

The aim of Regulation (EU) $2017 / 625$ is to lay down the basic requirements for the development and implementation of official food and feed control within the EU for all Member States. It replaces the previous Regulation (EU) 882/2004. In contrast to other previous regulations, the fight against food fraud comes into the focus. The former risk-oriented approach is no longer exclusively limited to food safety, but also includes the risk of food fraud. One important point of this new regulation is the statement that competent authorities "should have access to updated, reliable and consistent technical data, to research findings, new techniques and expertise necessary for the correct application of Union legislation". With this point in mind, the European Commission for the first time recommended the installation of National References Centres for the authenticity and integrity of the agri-food chain (article $97 \mathrm{ff}$ ) in the member states. Article 98 of Regulation (EU) 2017/625 defines responsibilities and tasks of the reference centres:

- providing specialized knowledge in relation to the authenticity and integrity of the agri-food chain and to the methods for detecting violations of the rules;
- providing specific analyses designed to identify the segments of the agri-food chain that are potentially subject to violations of the rules;

- establishing and maintaining collections or databases of authenticated reference materials;

- disseminating research findings and technical innovations.

In May 2017, the Federal Ministry of Nutrition and Agriculture (BMEL) in Germany decided to establish the National Reference Centre for Authentic Food (NRZ-Authent) at the Max Rubner-Institut (MRI), the Federal Research Institute of Nutrition and Food. Research at the MRI focuses on consumer health protection in the nutrition sector. The institute advises the Federal Ministry of Food and Agriculture in this area. MRI was founded on the 1st of January 2008 as the successor to the Federal Research Centre for Nutrition and Food (BfEL). In addition to its headquarters in Karlsruhe, MRI also conducts research at centres in Kiel, Detmold and Kulmbach (Max Rubner-Institut, 2018) (Fig. 1).

The MRI covers the whole food chain from the unprocessed raw materials to the processed food. In addition, MRI has comprehensive knowledge in food technology combined with different facilities for the production of different kind of food, such as bakery products, edible oil, meat products, potato products or milk products. Moreover, one department of the MRI is specialized on food and process technology.

The testing of food authenticity has been a research focus at MRI for many years, the key subjects being the development of methods to discriminate between organic and conventional agricultural products, to detect adulterations of olive oil, argan oil or cactus seed oil, to identify specific fruits, vegetables, spices and herbs as well as animal species and to detect undeclared/forbidden food ingredients. For these purposes, the MRI applies targeted and untargeted analytical procedures such as, e.g., gas chromatography/liquid chromatography coupled to mass spectrometry, isotope ratio mass spectrometry and modern molecular biology techniques (among others, next generation sequencing and reverse-transcriptase-polymerase chain reaction).

\section{Organisation of the NRZ-Authent}

The NRZ-Authent is organized in a decentralized manner: the Director is located at the Kulmbach site of the MRI and coordinates the different activities related to food authenticity at all four MRI sites according to each site's individual focus area, i.e. Kulmbach (meat), Karlsruhe (vegetables and fruits), Detmold (cereals, potatoes and oils) and Kiel/Hamburg (milk and fish). The NRZ-Authent uses the long-term expertise of the different food-related departments of the MRI and an intensive cooperation between the food-related departments and the NRZ-Authent is foreseen.

In order to fulfil the tasks, the NRZ-Authent is subdivided in two infrastructure modules and four fields of work supported by a steering committee and technical committees (Fig. 2). The technical committees are advisory bodies for the steering committee and develop recommendations regarding the fields of work, determine the demand of the food control authorities, prioritize the topics, and identify cooperation 


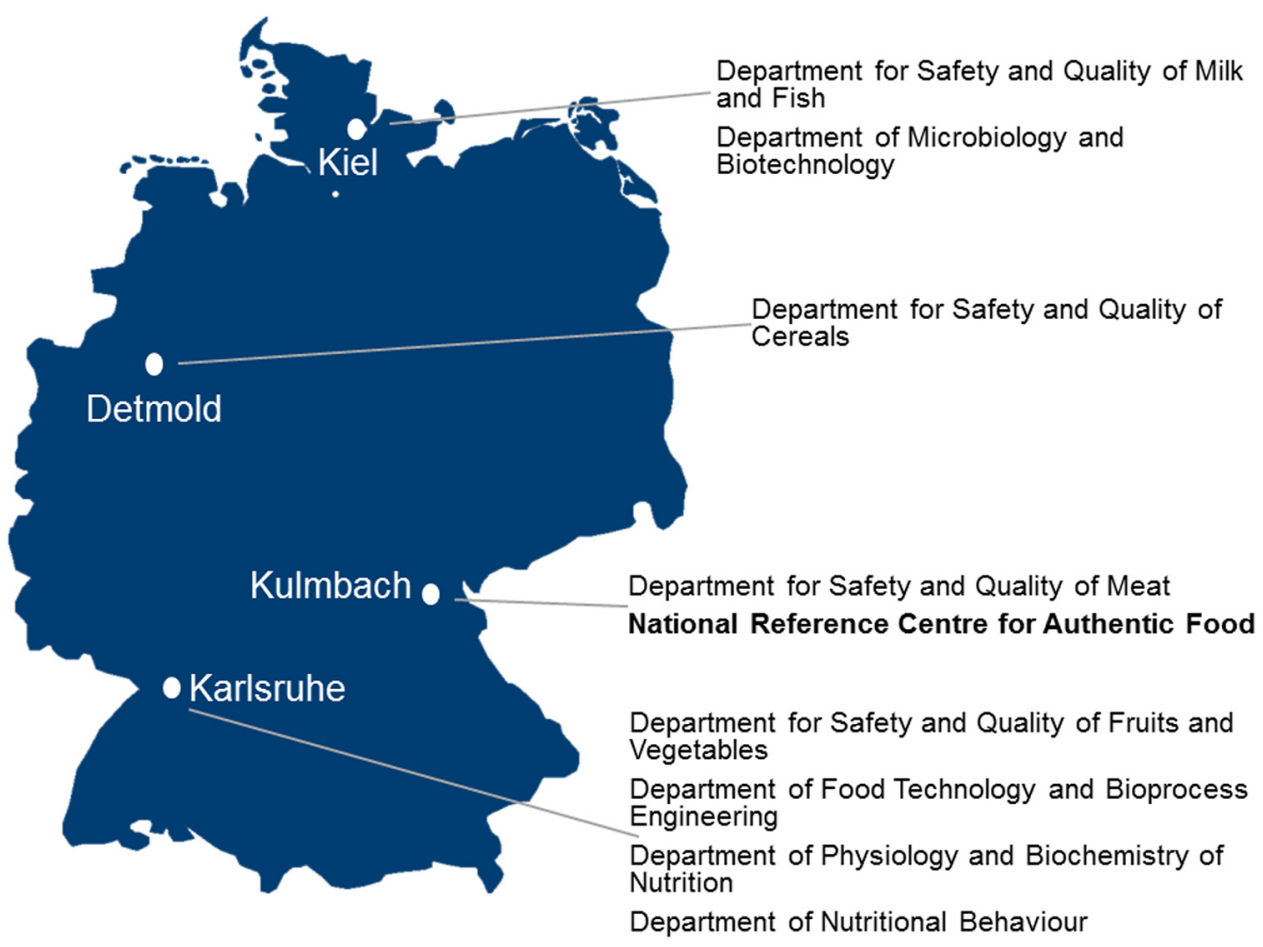

Fig. 1. Locations and departments of the Max Rubner-Institut, German Federal Research Institute of Food and Nutrition, which houses the NRZAuthent.

partners. The composition of these groups is flexible depending on the topic, and the groups consist of representatives of the MRI, the Federal Office of Consumer Protection and Food Safety (BVL) and/or the Federal Institute of Risk Assessment (BfR), food authorities and research institutions as well as other experts. In the steering committee, the president of MRI, the head of NRZ-Authent and representatives of BMEL, and BVL decide on the relevant topics to be tackled, the distribution of financial resources, the prioritization of the topics in different fields of work and the cooperations between the NRZ-Authent and different external organizations. The Joint Research Center in Geel (Belgium) (JRC) will act as an observer of the activities of the NRZ-Authent.

The tasks are accomplished (in accordance with the own MRI structure) across the different MRI sites. The main objective of the infrastructure module $\mathrm{I}$ is to put together and process internal and external data sets and information, which are passed on to the investigation offices in charge of controlling the food market via a communication platform to be established on the NRZ-Authent homepage. The main tasks of the infrastructure module II are the conversion of the newly developed methods into standardized routine laboratory methods, the accreditation of these new methods as well as the provision of certified reference materials and authentic food samples.

In addition to the two above-mentioned infrastructure modules, the NRZ-Authent is organized in four fields of work:

- verification of the geographic origin of food;

- verification of production methods;

- verification of adulterations/falsifications;

- species and variety differentiation.
The questions are answered in a demand-oriented way and by taking into account the own expertise present at MRI or in cooperation with other organizations such as BVL or BfR in Germany (see below).

\section{Duties and competences of the NRZ- Authent}

The main general aim of the NRZ-Authent is to pool and coordinate the activities related to the testing of food authenticity in Germany, in order to ensure the official food control authorities an easy access to up-to-date and reliable information, data and research results in this particular knowledge area.

In a first step, the NRZ-Authent has started with the setup, support and coordination of a network consisting of public authorities as well as organizations in the Länder (Federal States) and the Federal Government in Germany, all of them dealing with fraudulent and misleading practices along the food chain. In a second step, the NRZ-Authent will provide the network partners with a simple access to information on, e.g., scientific publications, new analytical methods and scientific meetings in the area of food authenticity testing. One possibility to make the information available could be the use of the "Fachinformationssystem für Verbraucherschutz und Lebensmittelsicherheit" (FIS-VL), which could also act as a platform for food control authorities to exchange information in a protected area in an interactive way.

In the frame of the above-mentioned network, the NRZAuthent will cooperate with different partners, as e.g., the offices in the Federal States in charge of food control, the BVL, 


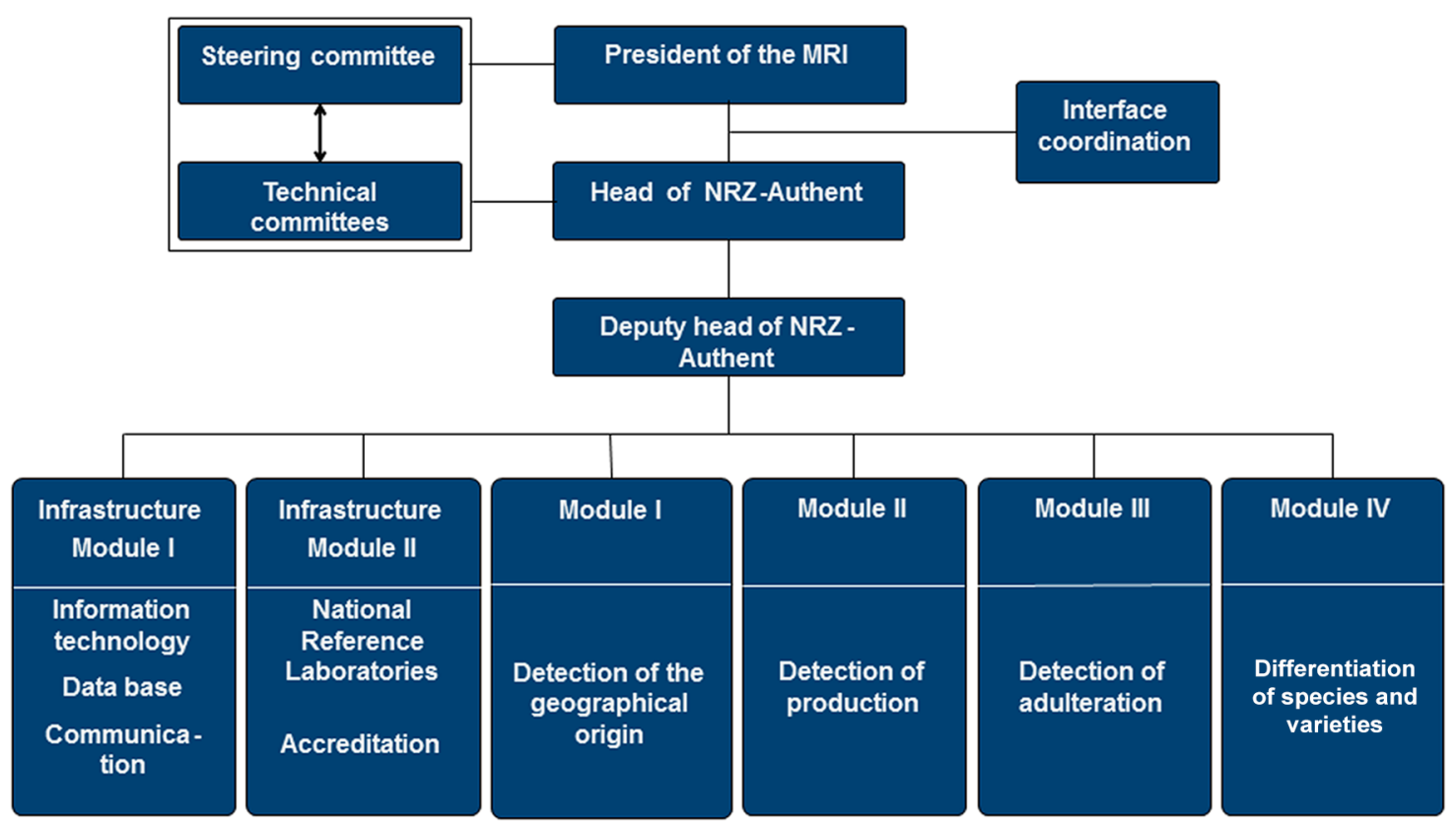

Fig. 2. Organigram of the National Reference Centre for Authentic Food (NRZ-Authent).

and JRC, which is specialized on the production and storage of reference materials including food. Further partners are the $\mathrm{BfR}$ and a number of research groups at universities and nonuniversity organizations in Germany, which address different aspects of food fraud.

In addition, the homepage of the NRZ-Authent, which can be accessed via the MRI homepage (Nationales Referenzzentrum, 2017), addresses the press, the interested public, and consumers. Further information exchange is made possible by organizing network partner meetings for all stakeholders. In this context, the MRI organized the 1st NRZ-Authent expert workshop (Bericht zum Expertenworkshop "NRZ EIL", 2017) in December 2017, in order to bring together experts from the food control laboratories in the Federal States. These constitute the core of the competence network, which will also be involved in the setup of the NRZ-Authent. During this workshop, the participants discussed which are the most important research topics, the importance of reference materials and authentic samples, the design of and the requirements for databases, the validity of new analytical methods for legal purposes and possibilities to prevent risks of fraud in the food chain. Finally, the NRZ-Authent received valuable information for the further roadmap on the way to its final setup stage during discussions in a World Café format.

A first NRZ-Authent workshop on the analytical differentiation of organic and conventional agricultural products took place in May 2018. Although methods to differentiate between organic and conventional products are available in the case of organic eggs (NMR) or organic milk (stable isotope analysis), most of the analytical methods only determine the probability that an adulteration has taken place. The main problem is the lack of databases and authentic reference materials. Another point is that the natural variability of characteristic features often is higher than the difference between organic and conventional food, thereby making the differentiation based on analytical methods difficult.
The 2ndNRZ-Authent expert workshop took place in November 2018 and focussed on the handling of scientific databases, the concrete organization of the communication within the network as well as strategies and methods to test the authenticity of olive oil.

A further key aspect of the NRZ-Authent is the ongoing development of analytical methods for the testing of the authenticity of food, e.g., the development of fast methods to be used by the food control authorities in the course of routine controls. These methods will only be developed at the NRZAuthent if the food control authorities are of the opinion that they are absolutely necessary and not available at any laboratory of the local food control authorities. This is the case of, e.g., the detection of not declared extraneous proteins and added extraneous protein hydrolysates in meat products, fast methods for the differentiation of fish species or the authentication of organic milk and organic fish (Nationales Referenzzentrum, 2017). An essential objective is the standardization and validation of new methods, so that they can be taken up in the official collection of analytical methods according to paragraph 64 of the German Food, Commodity and Feed Act (the "Lebensmittel-, Bedarfsgegenstände- und Futtermittelgesetzbuch") (Amtliche Sammlung von Untersuchungsverfahren, 2018). The NRZ-Authent acts as the contact organization for local food control authorities that want to know which method can specifically be used to test the authenticity of a certain food item. However, the NRZ-Authent is not a central testing facility that, e.g., will perform routine analyses for the Federal States.

Another important task of the NRZ-Authent will be the setup of a database on analytical methods that will be at the disposal of the food control authorities in the Federal States. The aim in this case is to build up a knowledge sitemap on food authenticity for Germany, which will include the information on which organizations (food control authorities, universities, private laboratories and/or private companies) test the 


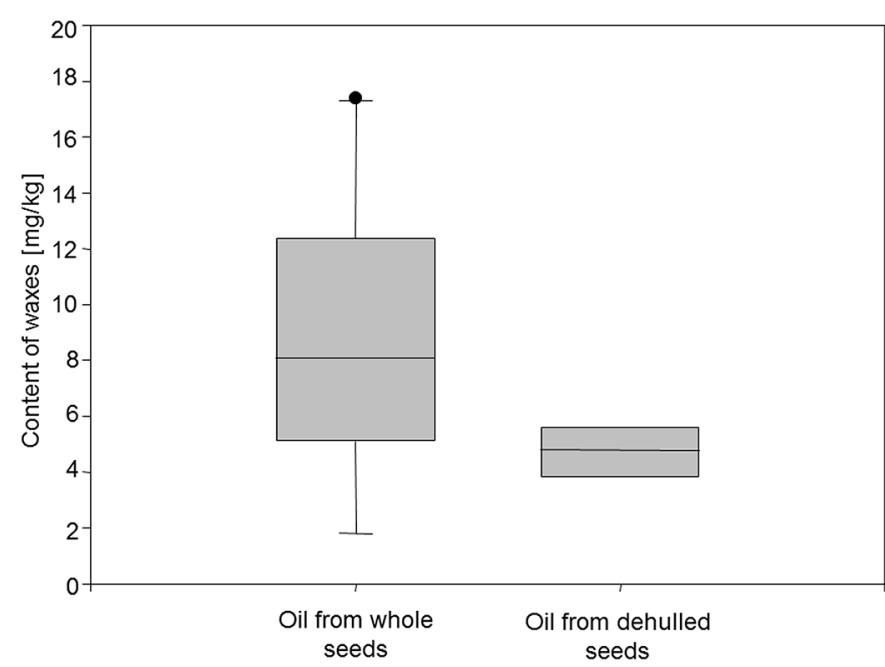

Fig. 3. Box-and-Whisker-Plot of the wax contents of oil from whole and dehulled seeds (ten samples per group).

authenticity of which food items or food groups with which methods. In this way, it should be possible to get a complete overview on the food authenticity research area in Germany and, by doing so, to systematically identify research gaps. Based on this overview, the Steering Committee of the NRZAuthent will be able to decide which steps need to be undertaken in order to fill in the identified research gaps.

\section{Activities on oil authenticity at the MRI}

One important aspect of the NRZ-Authent is the development and validation of analytical methods for the detection of adulterated edible oils, especially olive oil. Even if olive oil is not produced in Germany and its per capita consumption of about $1 \mathrm{~L} /$ year is low in comparison to the Mediterranean countries, it is a very popular and important oil for German consumers. In addition to olive oil, also other edible oils such as virgin rapeseed oil, cold-pressed argan oil or virgin cactus seed oil are in the focus of the MRI due to wrongly labelled quality or not declared or illegal processing. The MRI has a long tradition in the analysis on the quality of fats and oils and the development of methods to detect the adulteration of edible oils. Furthermore, scientists of the MRI lead the Joint Committee of the German Institute for Standardization (DIN) and the German Society for Fat Science (DGF) dealing with the analysis of fats, oils and products thereof. Furthermore, they are actively involved in the Expert Group of Olive Oil Chemists of the European Commission, the Olive Oil Chemistry and Standardization Group of the International Olive Council and the Codex Alimentarius. In the following three subchapters, studies on the authenticity of edible oils performed at the MRI are presented.

\subsection{Differentiation of virgin rapeseed oil from dehulled seeds and oil from whole seeds}

In Germany, unprocessed virgin rapeseed oil has become very popular, and its demand has continuously increased in the last ten years. Similar to olive oil, virgin rapeseed oil is processed by pressing the seeds with a screw press under gentle conditions and purification of the resulting oil by filtration or centrifugation only. Nowadays, virgin rapeseed oil from whole seeds as well as oil from dehulled seeds with a milder taste and smell and a more favourable composition due to the removal of the hulls are available. Removal of the hulls avoids the transfer of undesirable compounds into the oil. Therefore, advertising with virgin rapeseed oil from dehulled seeds is a valuable purchasing argument and producers as well as consumers of this type of oil are interested in avoiding the purchase of wrongly labelled oils.

One possibility to differentiate virgin rapeseed oil from dehulled and whole seeds could be the content of natural waxes normally located on the skin of the seeds. The content of waxes on rapeseed is relatively low in comparison to sunflower seeds, but amounts between 2 and $18 \mathrm{mg} / \mathrm{kg}$ can be detected. For the determination of waxes from edible oil, the ISO/ TS 23647:2010 method - Vegetable fats and oils - Determination of wax content by gas chromatography is used (ISO/ TS 23647:2010). The principle of the method is the isolation of waxes from the oil by column chromatography using a mixed column packing consisting of silica gel and silica gel impregnated with $\mathrm{AgNO}_{3}$ resulting in the separation of waxes from triacylglycerols and from other non glyceridic compounds containing unsaturated double bonds. Finally, the wax fraction is analysed by capillary gas chromatography with a FID detector.

The analysis of ten virgin rapeseed oils from dehulled seeds and ten from whole seeds shows that waxes in oil from dehulled seeds were detected in a narrow range of $4-6 \mathrm{mg} / \mathrm{kg}$, while the content of waxes in oil from whole seeds ranged between 2 and $18 \mathrm{mg} / \mathrm{kg}$ (Fig. 3). These results lead to the assumption that high amounts of waxes in virgin rapeseed oil are an indication that the oil was won from whole seeds, but low levels of waxes do not clearly characterize virgin rapeseed oil from dehulled seeds (Matthäus, 2006).

\subsection{Quality parameters of cold-pressed argan oil}

Cold-pressed argan oil is a very popular and expensive edible oil obtained from the kernels of the fruits of the argan tree (Argania spinose [L.] Skeels). The tree only grows in a particular area in the Southwest of Morocco, thereby resulting in a poor availability of the raw material and finally the oil. In addition, the production of the oil is very time-consuming in an ancestral multistep process, which consists in collecting and drying the fruits, the removal of the dried peels and the manual opening of the argan nuts to free the white kernels finally roasted indirectly in a gas burner to obtain the typical roasty taste of edible argan oil. Then, the roasted kernels are either subsequently crushed using a millstone resulting in a brownish viscous liquid that is mixed with water to free the oil after hand-malaxation for several minutes, resulting in an emulsion from which argan oil is finally decanted, or the kernels are pressed by a screw press resulting in a more effective and reliable processing. Because of the low availability and the time-consuming production process, edible argan oil belongs to the high-price oils with prices ranging between 50 and 140 Euro/liter, making the oil interesting for adulterations. 
In order to detect mixtures of argan oil with other edible oils, information on the natural variation of the most important constituents such as fatty acids, tocopherols, phytosterols or triacylglycerols to confirm its identity is important (Matthäus and Brühl, 2015). The oil is characterized by oleic acid and linoleic acid as predominant fatty acids. To confirm the authenticity of argan oil, the low level of $\alpha$-linolenic acid $(0.1 \%)$ could be helpful. The tocopherol composition is dominated by $\gamma$-tocopherol, which comprises about $90 \%$ of the total tocopherols. Especially the composition of the phytosterols distinguishes argan oil from other edible oils: it contains schottenol, which otherwise is only detected in pumpkin seed oil, tea seed oil and shea butter, and does not contain $\beta$-sitosterol, the main phytosterol of most other edible oils. More characteristic than the fatty acid composition is the composition of the triacylglycerols which predominantly consists of POO, PLO, OOO, OLO and LLO ${ }^{1}$ according to the fatty acid composition, thereby showing a very small variation. The results show that the triacylglycerol composition could be a very stable characteristic feature to confirm the identity of pure argan oil. While the fatty acid composition of adulterated oils often falls into specified limits, the triacylglycerol composition shows conspicuous features.

\subsection{Olive oil}

In comparison to other vegetable oils, the price that can be obtained for extra virgin olive oil is relatively high. Consequently, olive oil is very vulnerable to fraudulent practices. The Regulation (EU) No. 1308/2013 classifies three categories of native olive oils: extra virgin olive oil, virgin olive oil and lampante olive oil. The categories are characterized by different requirements regarding chemical and organoleptic quality parameters. Extra virgin olive oil is the highest quality class without any sensory defects, followed by virgin olive oil and lampante olive oil, which are of less quality. Within the EU only the categories "extra virgin" and "virgin" may be marketed by retailers. In Germany, almost exclusively virgin olive oils labelled as "extra virgin" can be found in food retail stores. However, official control bodies or consumer protection organizations have repeatedly reported products labelled as "extra virgin" that do not comply with the quality criteria of this category. These oils often did not meet the organoleptic requirements, as defects could be determined by a tester panel. The sensory analysis of virgin olive oils has to be carried out by a trained panel consisting of $8-12$ testers and is rather personnel-intensive and time-consuming. For this reason, screening methods that help to identify sensory defective oils are highly appreciated in the fight against fraud.

Near infrared spectroscopy (NIRS) is an ideal analytical technique for this purpose. Several NIRS models for the determination of parameters related to the oil quality have been described, e.g. for the analysis of the acidity, peroxide value, UV-absorption at $232 \mathrm{~nm}$ and $268 / 270 \mathrm{~nm}$, isomeric diacylglycerols or pyropheophytin A (Willenberg et al., 2019).

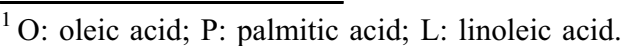

In comparison to the reference methods, the analysis using NIRS is characterized by a sample preparation that is reduced to a minimum, a short analysis time per sample and a quite easy handling. Furthermore, it is possible to analyse all the parameters within one single run. This advantage was used to develop a statistical approach to predict the organoleptic quality of olive oils based on the parameters free fatty acids, peroxide value, $\mathrm{K}_{232}, \mathrm{~K}_{270}$, isomeric diacylglycerols and pyropheophytin $\mathrm{A}$. The combination of these parameters in a logit regression model allows to calculate the probability of the presence of a sensory defect. As the percentage of accurately predicted samples was found to be $98.4 \%$ (Willenberg et al., 2019), this approach might be a helpful tool to identify potential fraudulent samples that have to be checked by a panel and thereby reducing the number of samples for the panels.

Conflicts of interest. The authors have declared no conflict of interest.

\section{References}

Administrative Assistance and Cooperation System. 2017. Available from: https://ec.europa.eu/food/safety/food-fraud/aas_en (last consult: 2018/16/12).

Amtliche Sammlung von Untersuchungsverfahren. 2018. Available from: https://www.methodensammlung-bvl.de (last consult: 2018/16/12).

BBC News - Q\&A: Horsemeat scandal. 2013. Available from: https:// www.bbc.com/news/uk-21335872 (last consult: 2018/16/12).

Bericht zum Experten workshop "NRZ EIL". 2017. Available from: https://www.mri.bund.de/de/nrz/forschung/bericht-expertenwork shop (last consult: 2018/16/12).

EUR-Lex. 2017. Regulation (EU) 2017/625 of the European Parliament and of the Council of 15 March 2017 on official controls and other official activities performed to ensure the application of food and feed law, rules on animal health and welfare, plant health and plant protection products. Available from: https://eur-lex.europa.eu/legal-content/EN/TXT/?uri= celex\%3A32017R0625 (last consult: 2018/16/12).

Food Fraud. 2018. Available from: https://ec.europa.eu/food/safety/ food-fraud en (last consult: 2018/16/12).

García González DL, Aparicio R, Aparicio-Ruiz R. Olive oil. In: Morin J-F, Lees M. Food integrity handbook. Nantes: Eurofins Analytics Frans, 2018.

Gelpi E, de la Paz MP, Terracini B, Abaitua I, de la Camara AG, Kilbourne EM, Lahoz C, Nemery B, Philen RM, Soldevilla L, Tarkowski S, Syn WCSCTO. 2002. The Spanish toxic oil syndrome 20 years after its onset: a multidisciplinary review of scientific knowledge. Environ Health Perspect 110: 457-464.

ISO/TS 23647. 2010. Vegetable fats and oils - Determination of wax content by gas chromatography.

Matthäus B. 2006. Differentiation between native rapeseed oil from dehulled and whole seeds by determination of the waxes. 4th Euro Fed Lipid Congress. 1-4 October 2006, Madrid, Spain.

Matthäus B, Brühl L. 2015. Quality parameters for the evaluation of cold-pressed edible argan oil. J Verbr Lebensm 10: 143-154.

Max Rubner-Institut. 2018. Available from: https://www.mri.bund. de/en/about-us/the-mri/ (last consult: 2018/16/12).

Nationales Referenzzentrum für authentische Lebensmittel. 2017. Available from: https://www.mri.bund.de/de/nrz/forschung/ (last consult: 2018/16/12). 
B. Matthäus et al.: OCL 2019, 26, 11

Willenberg I, Matthäus B, Gertz C. 2019. A new statistical approach to describe the quality of extra virgin olive oils using near infrared spectroscopy (NIR) and traditional analytical parameters. Eur $J$ Lipid Sci Technol. 121: 1800361.

Cite this article as: Matthäus B, Willenberg I, Engert S, Steinberg P. 2019. The German National Reference Centre for Authentic Food (NRZ-Authent). OCL 26: 11. 